\title{
Resilience in flood risk management - Exploring its added value for science and practice
}

\author{
Jochen Schanze $e^{1,2, a}$ \\ ${ }^{1}$ Leibniz Institute of Ecological Urban and Regional Development (IOER) \\ ${ }^{2}$ Chair of Environmental Development and Risk Management, Technische Universität Dresden
}

\begin{abstract}
The concept of resilience has become more prominent in the disaster risk sciences and policy documents on disaster risk reduction such as the United Nations Sendai Framework of Action 2015-2030. Originating from physics, psychology and ecology, it currently gains interest in a number of other fields. In line with that, it has been adopted in flood risk management from different disciplinary perspectives. Therefore, the question about the meaning of the resilience concept for flood risk management occurs. The paper derives a core concept of resilience for flood risk management from an extensive literature review. Hereby, it reflects the scope and characteristics of elements and (sub-)systems relevant to governing flood risks. It then integrates this concept in a comprehensive framework of risk management and differentiates it from similar concepts such as resistance, adaptability and transformability. Thereafter, the core concept is related to disciplinary views on resilience and particularly their operationalisation. The focus is on two examples of building constructions and risk management strategies. Interdependencies between application of resilience in these examples are discussed as well as similarities and distinctions of the disciplinary views are indicated. This leads to conclusions on the added value of the resilience concept for science and practice of flood risk management and to identification of questions for future research and implementation.
\end{abstract}

\section{Introduction}

Risks and impacts due to natural hazards and climate change are rising worldwide due to increase of human pressure on the natural environment with resulting environmental change and increase of human exposure and vulnerability triggered by societal change (e.g. [1, 2]). As a result, human-environment interrelations are getting more complex with accelerating dynamics and uncertainties and declining predictability (e.g. [3]). Limitations of analysing, predicting and controlling those interrelations max out "so-called precautionary principles" as far as they are based on detailed causeeffect calculations (cf. [4]). Thereby, the meaning of the receptors of environmental threats with their characteristics and performance is growing and elements or (sub-)systems at risk come to the fore in science and practice.

Resilience can be seen as one key concept referring to the performance of subjects, objects and systems under changing boundary conditions. It already has a history in a few science disciplines, mainly in physics, psychology and ecology, and today is gaining interest in numerous fields from their specific views. Environmental risk management and governance as great challenges of the presence involve some of these fields and hence need to tackle with a variety of resilience concepts (e.g. [5]). Moreover, they use resilience in relation to other

\footnotetext{
$\overline{{ }^{a} \text { Corresponding author: j.schanze@ioer.de }}$
}

concepts, which requires differentiation and specification (cf. [6]).

Flood risk management refers to the natural hazard causing one of the highest impacts (overall loss and fatalities) for the society globally in a long-term annual average (e.g. [2, 7]). Therefore, it is justified to shed more light on the current and potential added value of the resilience concept and its operationalisation in science and practice of this particular field. This mainly refers to the question of how to conceptualise and operationalise resilience for the rather different entities with their interdependencies relevant to flood risk management also considering respective disciplinary specificities.

\section{Resilience - Concept, integration and differentiation}

There is no common understanding of resilience due to its origin in different science disciplines and its specific adoption for various fields (e.g. [8]). Thus, particular conceptualisation is needed for the purpose of application. This conceptualisation, however, is challenging in case of a comprehensive field such as flood risk management. Accordingly and after a brief elucidation of environmental risk management and governance, this section tries to answered the following question: resilience of what to what (e.g. [9])? Based upon, a core concept of resilience is derived trying to be 
sufficiently generic on the one hand and allowing for linking to and specification by disciplinary resilience concepts on the other hand. In line with the thematic focus of this paper, relation of resilience to existing framing of flood risk management is explained then. Finally, differentiation from concepts with a connotation similar to resilience aims at further clarification and prevention of conceptual overlap. The entire investigation is based on an extensive literature review.

\subsection{The field of flood risk management}

Management of environmental risk can be defined as "systematic holistic and continuous analysis, evaluation and reduction of risk" ([10]; cf. ISO 31000) by actors covering all related issues such as planning, organising, staffing, directing and controlling (e.g. [11, 12]). Governance furthermore involves the institutional setting and the stakeholders with their networks and may be described as governance regime with a certain governance model (cf. [13, 14]). Thereby, institutions are systems of established and prevalent societal rules that structure social interactions. Stakeholders are those individuals or groups who have a stake in or claim on the issue like a firm or river basin (cf. e.g. [15]) and hence exceed the actors with their predominantly operational tasks. And networks can be understood as "a relatively stable horizontal articulation of interdependent, but operationally autonomous actors [here: stakeholders; the author] (i) who interact through negotiations that involve bargaining, deliberation and intense power struggles, (ii) which take place within a relatively institutionalised framework of contingently articulated rules, norms, knowledge and social imaginations and (iii) that is selfregulating within limits set by external agencies and which contribute to the production of public purpose in the broad sense of visions, ideas, plans and regulations“" ([16: 3]).

Flood risk management in this sense refers to risks due to flooding and is embedded in a governance context. Flooding is the principal threat that may occur as different flood types such as pluvial, flash, plain, coastal, estuarine and groundwater flood. Moreover, climate change and societal change can be drivers of change increasing or decreasing frequency, magnitude and other features of events. Risk is recognised as probability of (negative) consequences or interference of hazard and vulnerability depending on exposure (cf. [10, 17]). This means that flood risk in its cause-effect interrelation is about the threat from water and the exposure and vulnerability of receptors.

Vulnerability may be determined by value or function, susceptibility and coping capacity ([18]). While value or function regard to the societal meaning or purpose of an element or system at risk, susceptibility depicts its propensity to experience harm (ibid.). Although the term coping capacity has been dedicated to people by the (constructivist) social sciences first (e.g. [19]), it more broadly may be considered as ability to regain the initial state after external stress. Societal drivers may also influence the degree and long-term change of vulnerability and exposure.

Flood risk evolves in a flood risk system as systems' complex of numerous natural and societal elements and (sub-)systems with interconnecting processes ([20]). Hereby, elements are seen as parts of a system, maybe representing an internal system, and, according to natural and social science systems' theories, can be understood as entities in co-evolutionary interdependence with the system (cf. e.g. [21]). The flood risk system covers the flood hazard as the treat, the flood vulnerability as receptor of the threat and exposure of the latter to the former. As human-environment systems' complex, it is both biophysical (material) and immaterial.

Flood risk management deals with (i) the biophysical elements and (sub-)systems including their probability and uncertainty, (ii) the socio-cultural construction by the people affected, the actors responsible for management and the stakeholders of governance and (iii) finally governing of the risk (cf. [22]). As follows, these elements and (sub-)systems are explained a bit more deeply.

\subsection{Elements and systems relevant to resilience}

Since the question of resilience to what has been roughly answered in the previous section, now the what of resilience needs to be specified in more detail. Risk management and governance involve a variety of elements and (sub-)systems that could be at threat (cf. $[23,24])$. Classification of these elements and (sub-) systems should advert to their scope and characteristics. As follows, a number of categories with their subcategories are proposed to specify the general notion of the flood risk system as a systems' complex:

- Element

○ Subject (e.g. human being)

o Organism (e.g. plant)

○ Object (e.g. brick)

- (Sub-)System

- Social system (e.g. organisation)

○ Ecological system (e.g. lake ecosystem)

○ Technical system (e.g. building)

- Systems' complex

○ Social systems' complex (e.g. municipality)

○ Ecological systems' complex (e.g. stream network)

○ Technical systems' complex (e.g. infrastructure network)

○ Human-environment systems' complex (e.g. floodrisk system)

Governing these elements and (sub-)systems may also be considered from a resilience perspective, although it regards more to a process (management) embedded in a regime (governance) instead of an element or system in the aforementioned sense:

- Management and governance

- Management of actors with their strategy

○ Governance with institutional setting and stakeholders with their networks 
Each (sub-)category involves particular disciplines with their resilience concepts. Interdependencies between the (sub-)categories in the context of flood risk management ask for conceptualisation of resilience in a way that allows for both a common basic meaning and as far as possible - linking to disciplinary specifications.

\subsection{Derivation of a core concept of resilience}

Independent disciplinary evolution of the resilience concept is the main reason for diversity of its meaning. Nowadays, intensive treatment of resilience additionally has led to an increasing divergence of disciplinary and thematic concepts respectively (e.g. [4, 25, 26, 27]). Conceptualisations relevant to flood risk management last from psychology and civil engineering to organisational research. Psychology originally used the understanding of an invulnerability under straining circumstances, but in the meantime broadened this view to also cover the capability to deal with strain etc. ([28]). Civil engineering for instance applies the definition of the capability to recover functionality (cf. [29]; see Figure 1). In organisational research, resilience describes structures and processes of organisational capacity in response to causes and impacts of disasters ([26]) or more specific "the capacity to cope with unanticipated dangers after they have become manifest, learning to bounce back" ([30]). Especially the notion of to bounce or jump back coincides with the Latin word 'resilo'.

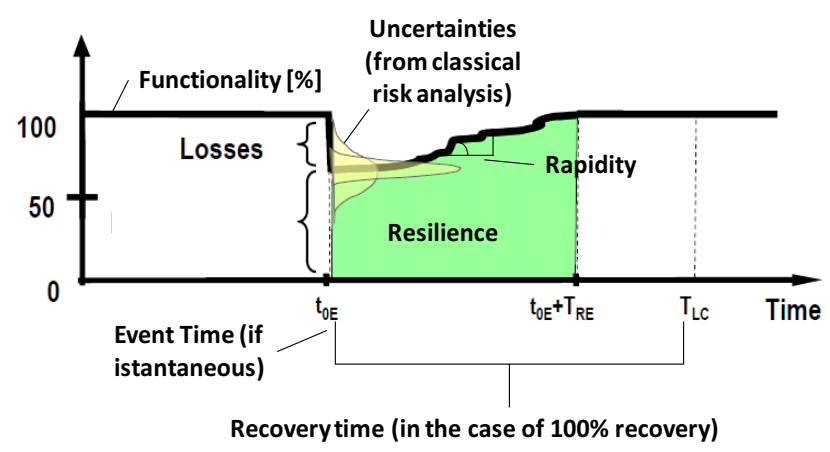

Figure 1. Functional resilience with degree of recovery and rapidity regarding functionality $([29$, modified $])$

There are a few features of resilience seeming to be relevant for a number of resilience concepts in the natural, engineering and social sciences. These are:

- The behaviour of an element or system under discontinuous sudden or creeping boundary conditions (e.g. [31]);

- Discontinuity may be sudden through an extreme event or incremental through long-term change. Moreover, it might be expected and/or unexpected (cf. e.g. [30]);

- Impacts from this discontinuity on the element or (sub-)system depend on both the magnitude and other features of the discontinuity and characteristics of the element or (sub-)system affected (e.g. 9, 24]);

- The behaviour refers to the capability of the element or (sub-)system to absorb disturbance and retain essentially the same function, structure, identity and feedbacks with the potential to continue development and to undergo re-organisation (e.g. [27, 32]);

- Recovery can be determined as degree of similarity of the characteristic structures and processes of the element or (sub-)system prior to and after suffering impacts from altered boundary conditions. It may be limited to a certain magnitude of the impact and additionally described by the required time, resources and patterns (e.g. [9, 29]);

- The ability may also encompass means of learning from previous events and respective behaviour (e.g. $[33,34])$;

- The behaviour and capacity to recover respectively are descriptive in the first instance and in principle are expected to be measureable (e.g. tipping points; e.g. [35]).

From these features the following core concept of resilience for flood risk management is derived trying to consider all previously mentioned elements and (sub-) systems with their management and governance: ability of an element or (sub-)system (as well as management strategy and governance regime) to regain characteristic features (maybe undergoing reorganising) and to continue development after disturbance (sudden) or change (creeping) of boundary conditions (cf. e.g. [31, 36]). It may be comprehended as elasticity in accomplishing (not avoiding) impacts from (a maximum) external stress with a certain degree of recovery and required time, resources and patterns and allows for understanding the system as equilibrium or dynamic evolution. The proposed core definition is neither restricted to one of the (sub-) categories nor bound to a discipline (cf. [37]). Instead, it serves as 'boundary object' for disciplinary specification (cf. [8, 34]). At the same time, it is focused enough to minimise overlap with related concepts (see Section 2.5).

Resilience in the proposed understanding is descriptive although it is commonly used because of its positive connotation (e.g. [25, 26]). A normative interpretation could limit its usability in science and practice ([8]). Evaluation, which is of particular interest for the science-policy-interface, additionally needs goals and targets. Science may elaborate on arguments, but judgement finally needs a societal mandate.

The proposed core concept steers the interest to the regain, recovery or return of the element or (sub-)system to a previous situation after disturbance or impacts from change of external boundary conditions. Hereby, the degree of reaching the previous features again and the respective time and even the required effort (resources) and requirements (patterns) may be considered. It is this particularity that makes resilience interesting, justifies detailed conceptualisation and calls for differentiation. In contrast, broadening resilience up too much and trying to cover all aspects of behaviour under external discontinuity would hardly make use of the potentials of a considerable new concept.

Beyond this framing of resilience for the element or (sub-)system under external discontinuity, management and governance allow for two additional perspectives: first, governing the resilience of elements and (sub-) systems, second, resilience of a management strategy or 
governance regime. In the second case, resilience for instance may be about the ability of dealing with unexpected disturbance or impacts of change in addition to anticipation of the future in the management strategy (cf. e.g. [30, 38]) or the capacity in the governance regime to bag the resilience of those strategies (e.g. [39]).

\subsection{Resilience related to disaster risk management}

In the context of risk as probability of (negative) consequences (cf. [10, 40]) or interference of hazard (or climatic stress) and vulnerability depending on exposure (cf. [17]), resilience can be regarded as one aspect of vulnerability. More particularly, the proposed core concept largely fits the coping capacity. Both address the ability to regain from disturbance or impacts from change. Resilience in comparison to vulnerability in general and coping capacity in particular more explicitly stresses the dynamics of recovery. This means that the resilient behaviour especially matters after the hazard has already led to impacts. In contrast, susceptibility is about the strength of the element or (sub-)system to avoid such impacts before they occur.

A well-known example of resilience in flood risk management is wet-proofing of constructions such as buildings (e.g. [41]). In this case, risk reduction aims at solutions that enable a complete (quick and less-resource intensive) refurbishment after water has entered the construction. This can be reached by materials that may be easily dried after wetting. Conversely, dry-proofing is about keeping the water out of the building to prevent any refurbishment need after inundation of the area around the building.

\subsection{Differentiation of resilience from resistance, adaptability and transformability}

A couple of other concepts discussed in the literature seem to have a meaning rather similar to resilience. Hence, it makes sense to clarify their acceptation and identify differences to and possible overlaps with the proposed core concept of resilience. According to Walker et al. [32] and others, among others the following concepts play are role:

- Resistance

- Adaptability

- Transformability

Resistance origins from Latin resistentia and means 'defense' or 'resistance'. It may be understood as strength of an element or (sub-)system to withstand external stress (without elasticity). Walker et al. [32: 2] describe resistance as "the ease or difficulty of changing the system". Thus, it suits the aforementioned meaning of susceptibility propensity to experience harm from external disturbance or change.

Adaptability (Latin adaptare; synonym: 'adaptive capacity') in a narrow sense is explicitly about alteration of the element or (sub-)system (e.g. [31]]). It can be recognised as ability of a system to (autonomously or consciously) alter its characteristic features (efficiently and fast) to changing circumstances in a sense of (co-) evolution (e.g. [42, 43]). In the context of risk, it refers to the reduction of exposure and vulnerability (e.g. [31]) and in a broad sense may also comprise resilience ([1]). Since there are also concepts where resilience encompasses adaptability, the narrow understanding of adaptability is proposed to be used to facilitate differentiation from resilience.

Transformability describes the capacity to create a fundamentally new element or (sub-)system when boundary conditions make the existing element or system untenable (cf. [32]). Likewise to adaptability and in contrast to resilience, it is about transition of the system and not about recovery of characteristic structures and processes to a state similar to the previous one.

Adaptability and transformability in the context of risk refer to exposure and vulnerability on the whole, since the element or (sub-)system at risk may evolve or be consciously altered in all of its features. Evolution may follow trial and error of selection and, therefore, in case of human beings and societal systems mainly be unacceptable. Conscious alteration needs anticipation of the future and modifiability of the system's characteristic structures and processes. However, anticipation is restricted due to limitation of analysing, predicting and controlling future cause-effect interrelations (see above).

Resilience is unique compared to these three concepts since it focuses on recovery after disturbance or impact of change and includes the time, resources and patterns required to re-establish previous characteristic features while possibly undergoing re-organisation. Hence, it complements the view of resistance as strength on the one hand and adaptability and transformability as alteration on the other hand. The latter come especially into play once the impact from external stress exceeds the ability of resilience.

For preparation for the future, resilience may also be considered in case of unexpected boundary conditions (cf. [30]). Beyond known situations, it additionally fits situations with known or unknown unknowns (cf. [44]). Therefore, it complements linear precautionary strategies that address anticipated events through application of tailor-made design standards. Resilience may allow for recovery above design standards although it might be limited to certain margins such as tipping points (e.g. [35]). To emphasise complementary of resilience to the linear anticipatory approach, scholars have proposed that risk management strategies may consist of both anticipation and resilience aspects ([30, 38]). The former is preparing for the expected event, the latter for the unexpected course of a real disaster.

\section{Disciplinary concepts and operationalisation - Two examples}

Feasibility of the proposed core concept of resilience needs to be reflected in the context of disciplinary concepts and their operationalisation. Thus, this section explores whether the overarching concept may be sufficiently related to the ones of individual disciplines. In principle, this would require an in-depth investigation 
of all disciplines involved in flood risk management including the spectrum of interpretations by different authors. For this paper, two examples are selected that are supposed to have some explanatory value and may show interdependencies. The examples represent two completely different (sub-)categories of elements and (sub-)systems at risk and their management and governance: constructions (e.g. buildings) and management strategies. The former bear on the disciplinary perspective of civil engineering, the latter on the one of organisational research in the social sciences. Explanation puts emphasis on the operationalisation of resilience and respective approaches to reach at least some detail in the disciplinary understanding.

\subsection{Resilience of constructions}

Although already known in civil engineering, the resilience concept related to constructions under threat from flooding still has a short history (cf. e.g. [45-47]). It is especially used in the context of (wet-)proofing of buildings and infrastructure (e.g. [45, 48]). In this case, resilience means the ability of a construction to dry or be dried after it has been inundated and wetted (ibid.).

It is predominately operationalised as invers function to refurbishment needs for recovering from flood impacts with no remaining damage as indication of maximum resilience (e.g. [49]). In line with that, physical performance of so-called flood resilience technologies is investigated in water laboratories ([45, 49]). Findings are included in water depth-damage functions and simulated in damage models (cf. [47, 49]; see Figure 2). The degree of resilience is finally calculated as inversion of the remaining damage after implementation of flood resilience technologies.
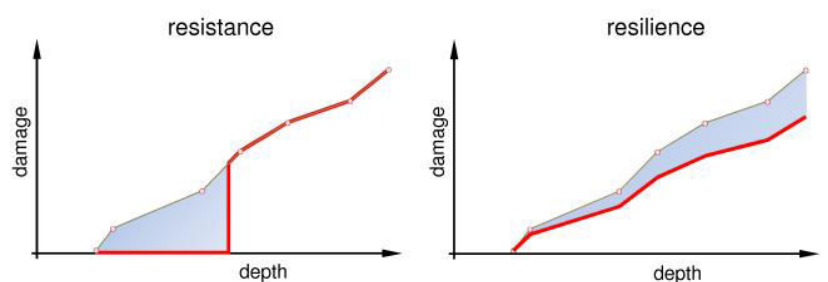

Figure 2. Generic depth-damage functions for implementation of resistance and resilience measures indicating effects of these measures (red line) and resulting savings (light blue area; [48, modified])

Measurement and simulation of the temporal dynamics of recovery in contrast to e.g. earthquake disaster risk reduction (see Fig. 1) did not play a major role in flood disaster risk reduction research so far but would be of interest for future research. In any case, resilience from this engineering view according to the material sciences may be distinguished from resistance of a building. The latter means the strength to withstand flooding without any impact and recovery (e.g. [50]).

\subsection{Resilience of risk management strategies}

The societal process of managing the risk falls in the disciplinary area of the social sciences with a particular interest in organisational research. In this context, one prominent conceptualisation of resilience bears on its contrast to anticipation (cf. [30]; ISO 22316 is under preparation). While anticipation "favors precise identification of possible difficulties so that specific remedies can be designed or recalled" ([33: 69]), resilience is about the capacity of using generalised and flexible resources to deal with the unexpected and to overcome failures once they occur. The unexpected may be 'radical' or 'incremental' once it is novel in relation to existing knowledge and beliefs ([34]). Since there are likely conditions that may partly be known and unknown, risk management strategies are supposed to be based on complementary consideration of both anticipation and resilience (cf. [30]).

In order to operationalise this organisational resilience, a number of criteria and indicators have been proposed (e.g. [30, 51, 52]). Recent research of Atanga ([38]) makes use of the former attempts of operationalising resilience. The author proposes six aspects of resilience with a number of ascertainable indicators and three aspects of anticipation again with respective indicators. In this case, anticipation can be interpreted as resistance in the aforementioned sense (see Section 2.5), since it aims at protecting the management process from unforeseen and unplanned challenges. The research in excess of individual organisations includes inter-organisational interrelations. The defined resilience aspects are as follows:

\begin{tabular}{|c|c|}
\hline Resilience aspect & $\begin{array}{c}\text { Criteria determining } \\
\text { resilience }\end{array}$ \\
\hline Omnivorousness & divers \\
\hline Homeostasis & $\begin{array}{c}\text { multiple } \\
\text { feedback loops }\end{array}$ \\
\hline Buffer capacity & $\begin{array}{c}\text { Over-dimensioned } \\
\text { capacity }\end{array}$ \\
\hline $\begin{array}{c}\text { Response process } \\
\text { and structure }\end{array}$ & flatness \\
\hline $\begin{array}{c}\text { Response resources } \\
\text { redundant }\end{array}$ \\
\hline Response rate & agile and timely flow \\
\hline
\end{tabular}

Table 1. Resilience aspects for flood risk management strategies $([38$, modified $]$ )

Empirical findings proof the feasibility of this analytical framework for an in-depth description of organisational resilience and its complementarity to anticipation.

\subsection{Interdependencies, similarities and distinctions}

Both examples are interdependent although representing two completely different (sub-)categories of elements or (sub-)systems with their management and 
governance. The management strategy may accomplish the task to analyse, evaluate and alter the resilience of the construction. In turn, the degree of engineering resilience influences the extent of uncertainties and thus the unexpected performance of the construction with its meaning for the share of resilience aspects in the management strategy. Accordingly, interrelations in the conceptualisation make some sense to coherently understand resilience. But how far does this coherence range?

Similarities in the case of the two examples and based on the proposed core concept of resilience refer to the recovery of characteristic features, namely the function of the construction and the response of the management strategy. Reorganisation might play a greater role for the management, but is also an issue during refurbishment of the damaged construction due to intervention in the existing construction. In both cases, threat may result from sudden or creeping variation of the boundary conditions and resilience describes a kind of elasticity in accomplishing the impacts with required time, resources and patterns. Interestingly, differentiation between resilience and resistance is also feasible for both examples.

Not surprising, there are fundamental distinctions in the specific disciplinary conceptualisation and operationalisation. Engineering resilience remains in a biophysical domain focusing the technical performance of materials and the construction. Description may bear on laboratory work and simulations. In contrast, organisational resilience deals with actors, stakeholders with their networks and the governance context. It is less measurable although some efforts are put into classifiable descriptions. Methods come from empirical social research ranging from stakeholder analysis to semistructured interviews and group discussions (e.g. [38]). The proposed core concept appears to leave sufficient room for these particularities, at least in the case of the two examples. Further in-depth investigation also comprising other (sub-)categories seems to be promising.

\section{Conclusions}

The paper has identified means of framing resilience in a way that cuts across many fields relevant to flood risk management. Thereto, it proposes a systematisation of elements and (sub-)systems that need to be addressed for the subject area. The designation of these elements and (sub-)systems already goes beyond the common notion of resilience of a so-called 'socio-ecological systems' (cf. [53]). The latter is often poorly described regarding its rather different natural and societal components with their interrelations. Moreover, its use without further explanation drives the risk of transferring findings on ecological systems to societal systems with lack of detailed reflection of particularities of disciplinary system theories and other knowledgebase. Of course, a single paper may not yet deliver the required theoretical discussion but point in a respective direction. More elaborated reference to current efforts in human ecology dealing with interrelations of different system theories could provide valuable insights in this regard (cf. [21]).

The proposed core concept derived for elements and (sub-)systems relevant to flood risk management turned out to be sufficiently specific as elasticity in accomplishing impacts from external stress with a degree of recovery and required time, resources and patterns. It allows for integration in a framework of flood risk management and differentiation from related concepts. Hence, there seem to be no reason for dismissing the existing frameworks of flood risk management. Instead, resilience has the potential for specification, particularly referring to a more dynamic representation of disturbance and impacts from change. Typical questions are: How far may an element or (sub-)system regain after an unavoided impact has occurred? How much time and which resources and pattern are needed for recovery? What are the requirements for reaching a particular level of resilience?

This specificity of resilience marks its added value (e.g. [54]). In contrast, a general notion of all features of covering external stress would neither respects the additional notion nor allow for its differentiation from previous means of risk reduction. In line with that, Lhomme et al. ([50]) and others stress that (precautionary; the author) reduction of impacts is not new and hence would question just to superimpose another term.

The proposed core concept of resilience seems to be sufficiently defined to focus on the above mentioned questions. Basic consistency may contribute to tackle with cross-disciplinary interdependencies and facilitate communication. At the same time, the core concept leaves some room for specification and operationalisation in rather different disciplines. This is visible from the briefly explained examples on constructions and flood risk management strategies. Of course, these two examples cannot properly represent the entire subject area yet. Further research is required to gain a more comprehensive view.

Requirements for reaching a certain extent of resilience obviously demand for certain efforts. This could mean to introduce redundancy in the applied measures and instruments for risk reduction. This redundancy very likely lowers efficiency as benefit-cost ratio (e.g. $[50,55])$. As consequence, resilience independent from its emphasis on coping with floods may stand in a tense relationship to the well justified aim of efficiently spending resources.

In addition to the previous questions on how to describe resilience, the expected conflict between resilience and efficiency poses the normative question on how much resilience is requested for? Trying to answer it involves some efforts in measuring and monetarising resilience according to the descriptive questions. It also faces the situation that there are not always suitable methods available also considering the differentiation from other concepts such as they have been mentioned earlier in this paper. For example, actors with their strategies need advice on how to properly combine resilience with resistance for a concrete flood risk management issue: What may be anticipated? What could 
remain unexpected? How to deal with the expected and unexpected? How to combine respective efforts most effectively? Thus, resilience can especially support decision makers in tackling with the fact that each flood disaster event is unique and may require performance outside anticipated boundaries. Furthermore, it stresses the required time, resources and patterns for recovery which gain growing attention because of increase in flood frequencies and magnitudes worldwide resulting from climate and societal change.

\section{References}

1. IPCC (2014). Climate Change 2014: Impacts, adaptation, and vulnerability. Part A: Global and Sectoral Aspects. Contribution of Working Group II to the Fifth Assessment Report of the Intergovernmental Panel on Climate Change. Cambridge, Cambridge University Press. Retrieved from https://ipcc-wg2.gov/AR5/report/full-report/ [accessed $13^{\text {th }}$ June 2014]

2. CRED, UNISDR (2016). The human cost of weather related disasters 1995 - 2015. Retrieved from http://www.unisdr.org/2015/docs/climatechange/CO P21_WeatherDisastersReport_2015_FINAL.pdf. [accessed $13^{\text {th }}$ March 2016]

3. Aster, R. (2012): Expecting the Unexpected: Black Swans and Seismology. Seismol. Res. Lett., 83(1). doi: $10.1785 /$ gssrl.83.1.5

4. De Bruijne, M., Boin, R. A. and van Eeten, M. (2010). Resilience: Exploring the concept and its meanings. In: Comfort, L. K., Boin, A., Demchak, C. C. (eds.), Designing resilience: Preparing for extreme events. Pittsburgh, PA, University of Pittsburgh Press, 13-32.

5. Cutter, S. L., Barnes, L., Berry, M., Burton, C., Evans, E., Tate, E. and Webb, J. (2008). A placebased model for understanding community resilience to natural disasters. Global Environmental Change 18, 598-606.

6. Walker, B., Gunderson, L., Kinzig, A., Folke, C., Carpenter, S. and Schultz, L. (2006). A handful of heuristics and some propositions for understanding resilience in social-ecological systems. Ecology and Society, 11(1), 13.

7. Munich Re (2016). Natural catastrophes 2015; Analyses, assessments, positions. Topic Geo 2016. Retrieved from http://www.munichre.com/site/touchpublications/get/documents_E1273659874/mr/assetp ool.shared/Documents/5_Touch/_Publications/30208875_en.pdf. [accessed $27^{\text {th }}$ March 2016]

8. Brand, F. S. and Jax, K. (2007). Focusing the meaning(s) of resilience: Resilience as a descriptive concept and a boundary object. Ecology and Society, 12(1), 23.

9. Carpenter, S., Walker, B., Anderies, J. M. and Abel, N. (2001). From Metaphor to Measurement: Resilience of What to What? Ecosystems, 4(8), 765781.

10. Schanze, J. (2006). Flood Risk Management - A Basic Framework, In: Schanze, J., Zeman, E. and
Marsalek J. (eds.), Flood risk management - Hazard, vulnerability and mitigation measures. Dortrecht, Springer, 1-20.

11. Weihrich R. and Koontz H. (1992). Management. New York, McGraw-Hill.

12. Gomez-Mejia, L. R. and Balkin, D. (2011). Management - People, performance, change. Boston, Prentice Hall.

13. Hufty, M. (2011). Investigating policy processes: The governance analytical framework (GAF). In: Wiesmann, U. and Hurni, H. (eds.), Research for sustainable development: Foundations, experiences and perspectives. Geographica Bernensia, 2011, 403424.

14. Montfort, van, C., Michels, A. and Frankowski, A. (2014). Governance Models and Partnershipsin the Urban Water Sector: A framework for analysis and evaluation. Tilburg/Utrecht, Utrecht University Repository, 15-04-2014. Retrieved from http://dspace.library.uu.nl/handle/1874/303566 [accessed 13 ${ }^{\text {th }}$ January 2015]

15. Freemann, R. E. (2001). A stakeholder theory of the modern corporation. Perspectives in Business Ethics Sie, 3, 38-48.

16. Sørensen, E. and Torfing, J. (2007). Introduction Governance Network Research: Towards a Second Generation. In: Sørensen, E. and Torfing, J. (eds.), Theories of democratic network governance. Houndmills, Palgrave Macmillan, 1-21. doi: $10.1057 / 9780230625006$

17. UNISDR (2009). Terminology on disaster risk reduction. Retrieved from www.unisdr.org/files/ 7817_UNISDRTerminologyEnglish.pdf. [accessed $20^{\text {th }}$ February 2010]

18. Blanco-Vogt, A. and Schanze, J. (2014). Conceptual and methodological frameworks for large scale and high resolution analysis of the physical flood susceptibility of buildings. Natural Hazards and Earth System Sciences, 14, 2105-2117. doi: 10.5194/nhess-14-2105-2014

19. Blaikie, P., Cannon, T., Davis, I. and Wisner, B. (1994). At risk: Natural hazards, people's vulnerability, and disasters. London, Routledge.

20. Schanze, J. (2016). Understanding land as part of the flood risk system and its governance. Journal of Flood Risk Management (under review).

21. Tretter, F. and Haliday, A. (2012). Modelling socioecological systems: Bridging the gap between natural and social sciences. In: Glaser, M. et al. (eds.), Human-nature interaction in the anthropocene. Potentials of socio-ecological system analysis. New York, Routledge Chapman \& Hall, 60-89.

22. Aven, T. and Renn, O. (2010). Risk Management and Governance. Concepts, Guidelines and Applications. Berlin, Springer.

23. Andries, J. M., Janssen, M. A. and Ostrom, E. (2004). A framework to analyze the robustness of social-ecological systems from an institutional perspective. Ecology and Society 9(1), 18.

24. Folke, C. (2006). Resilience: the emergence of a perspective for social-ecological systems analyses. Global Environmental Change, 16(3), 253-267. 
25. Gallopin, G. C. (2006). Linkages between vulnerability, resilience, and adaptive capacity. Global Environmental Change, 16, 293-303, doi: 10.1016/j.gloenvcha.2006.02.004

26. Comfort, L., Boin, A. and Demchak, C. (2010). Designing Resilience - Preparing for Extreme Events. Pittsburgh, University of Pittsburgh Press.

27. Folke, C., Jansson, Å., Rockström, J., Olsson, P., Carpenter, S., Chapin, F., Crépin, A.S., Daily, G., Danell, K., Ebbesson, J., Elmqvist, T., Galaz, V., Moberg, F., Nilsson, M., Österblom, H., Ostrom, E., Persson, A., Peterson, G., Polasky, S., Steffen, W., Walker, B. and Westley, F. (2011). Reconnecting to the Biosphere. AMBIO, 0044-7447. doi: 10.1007/s13280-011-0184-y.

28. Winders, S. (2014). From extraordinary invulnerability to ordinary magic: A literature review of resilience. Journal of European Psychology Students 5(1), 3-9. doi: http://dx.doi.org/10.5334/jeps.bk

29. Bruneau, M., Chang, S. E., Eguchi, R. T., Lee, G. C., O’Rourke, T. D., Reinhorn, A. M., Shinozuka, M., Tierney, K., Wallace, W. A. and von Winterfeldt, D. (2003). A framework to quantitatively assess and enhance the seismic resilience of communities. Earthquake Spectra 9(4), 733-752.

30. Wildavsky, A. (1991). Searching for Safety. New Brunswick, NJ Transaction Press.

31. Nelson, D.R., Adger, W.N. and Brown, K. (2007). Adaptation to environmental change: Contributions of a resilience framework. The Annual Review of Environment and Resources, 32, 395-419, doi: 10.1146/annurev.energy.32.051807.090348

32. Walker, B., Holling, C. S., Carpenter, S. R. and Kinzig, A. (2004): Resilience, adaptability and transformability in social-ecological systems. Ecology and Society 9(2), 5. URL: http://www.ecologyandsociety.org/vol9/iss2/art5

33. Weick, K.E., Sutcliffe, K. (2007). Managing the unexpected. Resilient performance in an age of uncertainty. San Francisco, Jossey-Bass.

34. Hutter, G. (2013). Organizing social resilience in the context of natural hazards: a research note. Natural Hazards, 67, 47-60. doi: 10.1007/s11069-010-9705-4

35. Lenton, T.M. and Ciscar, J.C. (2013) Integrating tipping points into climate impact assessment. Climate Change 117(3), 585-597.

36. Miller, F., Osbahr, H., Boyd, E., Thomalla, F., Bharwani, S., Ziervogel, G., Walker, B., Birkmann, J., Van der Leeuw, S., Rockström, J., Hinkel, J., Downing, T., Folke, C. and Nelson D. (2010). Resilience and vulnerability: complementary or conflicting concepts? Ecology and Society 15(3), 11.

37. Godschalk, D. (2003). Urban Hazard Mitigation: Creating Resilient Cities. Natural Hazards Review, 4(3), 136-143. doi : 10.1061/(ASCE)15276988(2003)4:3(136)

38. Atanga, R. A. (2016). Flood risk management strategies and resilience: The capacity of key stakeholders to respond to the unexpected course of flood disasters in the city of Accra, Ghana. (in press).
39. Hutter, G., Kuhlicke, C. (2013). Resilience, talk and action - exploring the meanings of resilience in the context of planning and institutions. Planning Practice and Research, 28(3), 294-306. doi: 10.1080/02697459.2013.787706

40. Knight F. (1921) Risk, uncertainty and profit. New York, Harper \& Row.

41. De Moel, H., van Vliet, M. and Aerts, J.C.J.H. (2014). Evaluating the effects of flood damagereducing measures: a case study of the unembankded areas of Rotterdam, the Netherlands. Regional Environmental Change 14, 895-908. doi: 10.1007/s10113-013-0420-z

42. Smit, B. and Wandel, J. (2006). Adaptation, adaptive capacity and vulnerability. Global Environmental Change, 16(3), 282-292. doi: 10.1016/j.gloenvcha.2006.03.008

43. Walker, B. and Salt, D. (2012). Resilience Practice: Building Capacity to Absorb Disturbances and Maintain Function. Conneticut, Island Press.

44. Toth, F.L. (2008). Dealing with surprises in environmental scenarios. In: Alcamo, J. (ed.). Environmental futures: the practice of environmental scenario analysis. Amsterdam, The Netherlands, Elsevier, 169-193.

45. Escarameia, M., Karanxha, A. and Tagg, A. (2007). Quantifying the flood resilience properties of walls in typical UK dwellings Building Services Engineering Research and Technology 28, 249-263.

46. Zevenbergen, C. (2010) Towards flood resiliient cities. In: Ryon, Z., Zevendingen, C., Grau, D. and Kekez, Z. K. (eds), Building with Water. Concepts Typology Design. Berlin, Birkhäuser Verlag AG.

47. Mebarki, A., Valencia, N., Salagnac, J. L. and Barroca, J. L. (2012). Flood hazards and masonry constructions: a probabilistic framework for damage, risk and resilience at urban scale. Natural Hazards Earth System Sciences, 12, 1799-1809. doi:10.5194/nhess-12-1799-2012

48. Naumann, T., Nikolowski, J., Golz, S. and Schinke, R. (2010). Resilience and Resistance of Buildings and Built Structures to Flood Impacts - Approaches to Analysis and Evaluation. In: Müller, B. (Ed.). Urban Regional Resilience: How Do Cities and Regions Deal with Change? German Annual of Spatial Research and Policy, 2010. Berlin, Heidelberg, Springer, 89-100.

49. Golz, S., Schinke, R. and Naumann, T. (2015). Assessing the effects of flood resilience technologies on building scale. Urban Water Journal, 12(1), 3043. doi: 10.1080/1573062X.2014.939090

50. Lhomme, S., Serre1, D., Diab, Y. and Laganier, R. (2013). Analyzing resilience of urban networks: a preliminary step towards more flood resilient cities. Natural Hazards Earth System Sciences, 13, 221230. doi: 10.5194/nhess-13-221-2013

51. McManus, S., Seville, E. Brunsdon, D. and Vargo, J. (2007). Resilience management: A framework for assessing and improving the resilience of organisations. Resilient Organisations Research Report 2007/01. New Zealand, Resilient Organisations Programme. 
52. Wardekker, J.A., de Jong, A., Knopp, J.M. and van der Sluijs, J.P. (2010). Operationalizing a resilience approach to adapting a delta to uncertain climate changes. Technological Forecasting and Social Change, 77, 987-998. doi: 10.1016/j.techfore.2009. 11.005

53. Walker, B., Gunderson, L., Kinzig, A., Folke, C., Carpenter, S., Schultz, L. (2006). A handful of heuristics and some propositions for understanding resilience in social-ecological systems. Ecology and Society, 11(1), 13.

54. Klein, R. J. T, Nicholls, R. J. and Thomalla, F. (2003). Resilience to natural hazards: How useful is this concept? Global Environmental Change Part B: Environmental Hazards, 5, (1-2), 35-45. doi:10.1016/j.hazards.2004.02.001

55. Ouyang, M., Duenas-Osorio, L. and Min, X. (2012). A three-stage resilience analysis framework for urban infrastructure systems. Structural Safety, 3637, 23-31. doi.org/10.1016/j.strusafe.2011.12.004 